\title{
The Level of General Physical Performance and Physical Development of 10-Year-Old Pupils
}

\author{
Ivan Čillík, Juraj Kremnický, Rastislav Kollár, Pavol Pivovarniček and Martina Mandzáková \\ Department of Physical Education and Sport, Faculty of Arts, Matej Bel University, Banská Bystrica 975 49, Slovakia
}

\begin{abstract}
This contribution deals with the level of general physical performance of 10-year-old male and female pupils attending primary schools. Fourth grade pupils attending primary schools in Banská Bystrica were tested in the number of 433 pupils (220 boys and 213 girls). The following indicators of general physical performance were monitored: sit-and-reach, standing long jump, sit-ups, flexed arm hang, shuttle run $4 \times 10 \mathrm{~m}$, endurance shuttle run. Also basic somatic indicators such as body height, body weight and BMI were found out. 10-year-old boys achieve better level in five tests of general physical performance. The girls achieve statistically better level in one test. When comparing it with the previous researches in Slovakia, we noted a lower level of general physical performance but a higher level of indicators of physical development of boys and girls from Banska Bystrica. Used set of tests affects the whole range of general physical performance, and it is adequate to the temporal, spatial and material conditions of schools.
\end{abstract}

Key words: primary schools, physical education, 10-year-old pupils, general physical performance, somatic characteristics.

\section{Introduction}

Recently, many experts have been dealing with the question whether physical performance decreases or increase in recent years. In general, there has been stated the low level of general physical performance, growth in the number of overweight and obese children, deterioration of health, a greater number of children with muscle imbalances and weaknesses, bad posture and last but not least, lower children`s interest in physical activity, sport and physical education. Nevertheless, we have noted different opinions. For example, Welk et al. [1] concluded that there is little objective data to support these claims. Mutual comparison of the results from different studies is complicated because of the variety of test batteries.

In Slovakia, there has been numerous studies dealing with physical development and general physical performance of pupils [2-10]. The results are different, as well as test batteries, abundance and

Corresponding author: Ivan Čillík, Ph.D., professor, research fields: sport training, track and field, physical performance.E-mail: Ivan.Cillik@umb.sk. representativeness of samples.

In recent years, studies by authors confirm the reducing level of general physical performance and the increasing level of indicators of physical development. This is also confirmed by our results on a group of 492 pupils attending the first classes in Banska Bystrica [11], when comparing them with previous researches $[7,8,12,13]$.

Motor performance of young school-age children is in most motor skills developed parallel with age. Differences between girls and boys are generally negligible. Boys consistently dominate in motor activities due to explosive power and speed when comparing them to girls. Girls are characterized by greater flexibility of the lower back $[12,14,15$, . Minimum differences are shown, boys are taller and heavier [16]. Relatively small differences in body disposal allow girl and boys effectively and fully participate in physical activities of the same type. The age of 10 is considered to be the most favorable period for motor development. Therefore, children are able to perform more difficult coordination-based exercises. Gross motor skills tend to develop and are in advance 
with the respect to the development of fine motor skills [17].

In the 20th century, particularly in 50s-60s, new test batteries focused on assessing of the physical fitness and performance of the school population were discovered in Western European countries and North America. In 1987, "the committee for the development of sport" at the Council of Europe, formulated the basic background of monitoring the physical development and motor performance of children and youth. In 1983 and 1988, an international group of experts and scientist gradually released monographs "EUROFIT" which summarized empirical results and determined the methodology of implementation of individual motor tests. The following tests were included to a test battery: "Flamingo" balance test, Plate Tapping, sit-and-reach test, standing long jump, sit-ups in 30s, flexed arm hang test, shuttle run $10 \times 5 \mathrm{~m}$, endurance shuttle run.

The part of a measuring physical fitness within "Eurofit" was also somatometry (body height, body weight, measuring the body fat percentage using skinfold test). Methodology of creating tests was gradually formed along the lines of a need for comprehensive assessment of the development of motor abilities of children and youth. Such motion tasks, that did not require any significant motor skill, were searched for. At the same time, such tests were selected which did not require challenging park equipment for their implementation. Gradually, the methodology of implementation of individual tests is specified so that its validity and reliability relatively and objectively demonstrated the level of development motor skills. From the point of view of motor performance, test items for assessing individual fitness and coordination skills were performed.

For evaluation of physical performance of the school population, standardized test batteries (e.g. EUROFIT [18], UNIFIT [19, 20], FITNESSGRAM [21], ACTIVITYGRAM [22]) were used. There also exist test batteries for the selection of talented individuals in sport [23]. There are also other known test batteries for the assessment of a general physical performance [24]. These mentioned test batteries are, by their nature and normative way of assessment the test results, focused on the performance component of physical fitness.

Based on the information of the previous reviews of physical fitness and physical performance of children, we conclude that the innovation of motor tests and verification should lead to a simplification of diagnosis and to an increase of the overall motivation of teachers and pupils for physical activity. In Slovakia, for detection of general physical performance and physical development, the test battery EUROFIT is mostly used. Therefore, we applied a set of tests that cover the full range of general physical performance, but by reducing the number of test items in comparing with the test battery EUROFIT.

The aim of this contribution is to find out the level of general physical performance and the level of physical development of the 10-year-old pupils in Banská Bystrica and then, to compare it with previous researches in Slovakia.

\section{Methodology}

This project is an agreement of cooperation between the town Banská Bystrica and Matej Bel University. The project was organized by Department of Physical Education and Sport at Matej Bel University, Faculty of Arts.

Overall, $75 \%$ (433 pupils) of the total number of 10 -year-old pupils 579 were tested. Remaining $25 \%$ were not tested because of the absence on teaching process or they could not exercise mainly because of the health reasons. There are 12 public schools in Banská Bystrica. One of the school is without a gym, therefore, these pupils were not tested as well [8]. The pupils were tested in the number of 220 boys and 213 girls. The average age of tested boys was $10.37 \pm 0.44$ decimal years during the measuring and the average 
age of tested girls was $10.21 \pm 0.4$ decimal years. So, the group of tested boys was older about 0.16 years.

Measurements were made by teachers and Ph.D. students, Master and Bachelor students during April-June, 2014. Testing of pupils was the part of a teaching process, usually implemented during Physical education lessons. The diagnostic of the level general physical performance was always implemented after the same pre-prepared warm-up and stretching of pupils in the gym. Measurements were made in accordance with daily biorhythms [25] always in the morning from 8 to 12 o'clock under the standard conditions of the gym at school, which pupils have attended. As a rule, one class was tested during one lesson.

Measuring process: After arriving to the gym, pupils received race numbers and they became familiar with the aim of the research. Basic identification data (name, date of birth, involvement in organized physical and sport activities) were provided by classroom teachers. Measuring of the level of physical development: body height, body weight. BMI was calculated on the basis of this. Measurement of body height was performed according to the methodology [7] to the nearest $0.5 \mathrm{~cm}$. Measurement of body weight was performed using a digital weight according to the methodology [7] to the nearest $0.1 \mathrm{~kg}$. Warming-up (3 min) and stretching (5 min). When selecting tests, we relied on 2 test batteries-Eurofit and Unifit. We used the following tests to find out general physical performance: sit-and-reach test, standing long jump, sit-ups in 30s, flexed arm hang, shuttle run $4 \times 10 \mathrm{~m}$, endurance shuttle run.

We applied a set of tests that cover the full range of general physical performance, but by reducing the number of test items in comparing with the mentioned test batteries. All the tests, sit-and-reach test, standing long jump, sit-ups, flexed arm hang and endurance shuttle run test, were performed according to the methodology [7]. Shuttle run $4 \times 10 \mathrm{~m}$ was performed according to the methodology [11]. The task was to cross the opposite or starting line with both feet. The time needed to overcome $4 \times 10 \mathrm{~m}$ was recorded to the nearest $0.1 \mathrm{~s}$.

The order of tests was not strictly followed due to time, but endurance shuttle run was always performed as the last one.

We used the chi-square goodness of a fit test to verify the representativeness of the subjects by sex. The representativeness was verified for standard use $5 \%$ significance level $(\alpha=0.05)$. The representativeness of gender selection was not rejected $(P=0.136)$.

We used a T-test for independent subjects to verify the difference in the performance of boys and girls. Statistically significant difference in performance was tested in:

(1) the level of general physical performance (in all implemented tests) between boys and girls;

(2) the level of physical development (body height, body weight, BMI) between boys and girls.

Statistical analysis was realized by using the software IBM SPSS Statistic 19.0.0.

We also used the following basic statistical characteristics of central tendency and dispersion when evaluating the results: arithmetic average (x), standard deviation (SD), minimum measured values (min) and maximum measured values (max) and percentages (\%). We used basic logical methods to evaluate and interpret the results.

\section{Results}

Results show a different level of monitored parameters in boys and girls (Tables 1 and 2). The girls achieve on average better level of trunk flexibility which was determined through a sit-and-reach test. Contrary, in boys, we recorded better average values in explosive power of lower limbs (standing long jump), dynamic endurance strength of abdominal and hip-thigh muscles (sit-ups), static and endurance strength of muscles of upper limbs (flexed arm hang), running speed with changes of 
Table 1 Monitored indicators of general physical performance in a group of 10-year-old boys (B).

\begin{tabular}{|c|c|c|c|c|c|c|c|c|c|c|}
\hline B & AGE & SRT & SLJ & SUT & FAH & $4 \times 10$ & ESR & $\mathrm{BH}$ & $\mathrm{BW}$ & BMI \\
\hline & & $(\mathrm{cm})$ & $(\mathrm{cm})$ & (n) & (s) & (s) & (n) & $(\mathrm{cm})$ & $(\mathrm{kg})$ & (i) \\
\hline $\mathrm{x}$ & 10.37 & 16.28 & $151.93 *$ & $19.75 *$ & 25.45 & $12.8^{*}$ & $37.08 *$ & 144.75 & $38.78^{*}$ & $18.36^{*}$ \\
\hline SD & 0.44 & 6.55 & 22.01 & 4.97 & 22.92 & 1.31 & 17.28 & 6.85 & 9.24 & 3.42 \\
\hline $\min$ & 9.57 & 0 & 66 & 6 & 0 & 10.2 & 9 & 125 & 22.3 & 13.2 \\
\hline $\max$ & 12.9 & 31 & 216 & 37 & 115 & 17.5 & 94 & 164.5 & 75 & 31.02 \\
\hline
\end{tabular}

SRT: sit-and-reach test; SLJ: standing long jump; SUT: sit-ups; FAH: flexed arm hang; $4 \times 10$ : the shuttle run $4 \times 10$ m; ESR: endurance shuttle run; BH: body height; BW: body weight; BMI: body mass index.

*statistically significant difference in favour of tested boys $(P$-value $<0.05)$.

Table 2 Monitored indicators of general physical performance in a group of 10-year- old girls (G).

\begin{tabular}{lllllllllll}
\hline G & AGE & SRT & SLJ & SUT & FAH & $4 \times 10$ & ESR & BH & BW & BMI \\
\hline & & $(\mathrm{cm})$ & $(\mathrm{cm})$ & $(\mathrm{n})$ & $(\mathrm{s})$ & $(\mathrm{s})$ & $(\mathrm{n})$ & $(\mathrm{cm})$ & $(\mathrm{kg})$ & $(\mathrm{i})$ \\
$\mathrm{x}$ & 10.21 & $20.62 *$ & 144.06 & 17.86 & 24.18 & 13.34 & 29.51 & 144.04 & 36.45 & 17.4 \\
SD & 0.4 & 6.46 & 18.51 & 4.44 & 19.22 & 1.03 & 13.46 & 6.63 & 8.23 & 2.91 \\
$\min$ & 9.48 & 5 & 85 & 2 & 0 & 10.6 & 5 & 122 & 20 & 12.9 \\
$\max$ & 12.34 & 36 & 199 & 35 & 81 & 16.2 & 85 & 162 & 67 & 28.5 \\
\hline
\end{tabular}

SRT: sit-and-reach test; SLJ: standing long jump; SUT: sit-ups; FAH: flexed arm hang; $4 \times 10$ : the shuttle run $4 \times 10 \mathrm{~m}$; ESR: endurance shuttle run; BH: body height; BW: body weight; BMI: body mass index.

*statistically significant difference in favour of tested girls $(P$-value $<0.05)$.

direction (shuttle run $4 \times 10 \mathrm{~m}$ ) and running endurance capacity (endurance shuttle run). We recorded statistically significant difference in the following tests: standing long jump, sit-ups, shuttle run $4 \times 10 \mathrm{~m}$ and endurance shuttle run in favor of boys and in the sit-and-reach test in favor of girls.

Referring to the level of maximum performance, differences in monitored tests are not as clear as in the average values. The girls achieved the best performance in the sit and reach test. The boys achieved the best performance in the following tests: standing long jump, sit-ups, flexed arm hang, shuttle run $4 \times 10 \mathrm{~m}$ and endurance shuttle run. Even in the worse performance level, the differences in monitored tests are not as clear as in the average values. The girls achieved the worst result in tests: sit-ups and endurance shuttle run. The boys achieved the worst result in tests: sit and reach test, standing long jump and shuttle run $4 \times 10 \mathrm{~m}$. There is one test in which the girls and boys achieved the same worst performance: flexed arm hang test. In the flexed arm hang test, we recorded zero values. It means that in both groups there were individuals who did not finish any cycle in the sit-up test.

In the group of boys, we also recorded higher average values of somatic indicators-body height (boys were on average higher by $0.71 \mathrm{~cm}$ ), body weight (boys were on average heavier by $2.23 \mathrm{~kg}$ ) and BMI was higher by 0.96. Statistically significant difference was found in body weight and BMI in favor of boys.

\section{Discussion}

When comparing our group of boys and girls, we conclude that the 10-year-old boys achieve better level in these five tests of general physical performance: standing long jump, sit-ups, flexed arm hang, shuttle run $4 \times 10 \mathrm{~m}$ and endurance shuttle run. The differences are statistically significant in four of them. The girls achieve statistically better level in trunk flexibility. Boys exceed the girls especially in the tests in which power, speed-strength and endurance capabilities are decisive. The results are similar with those of other authors, who mention that the results of boys in the tests of general physical performance according to EUROFIT, are significantly higher than 
the results of girls, except flexibility [5]. In contrast, other authors state that at the age of 9-11 years, the sex differences are not significantly shown in performance [26].

We compare the results of our groups with the group from Slovakia [7] and with the group of children from eastern Slovakia [8].

When comparing the performance of the group of boys with the group from Slovakia [7], we conclude lower level in all the tests, except the flexed arm hang test (Table 3). The boys from Banská Bystrica mostly lag behind in explosive power of lower limbs, dynamic and endurance strength of abdominal and hip-thigh muscles and in running endurance capacity. The comparison with the boys from eastern Slovakia shows bigger equality of both groups. The boys from Banská Bystrica are better in the following tests: flexed arm hang and endurance shuttle run. The boys from eastern Slovakia are better in the following tests: sit-and-reach test, standing long jump and sit-ups.

Comparing the group of girls from Banská Bystrica to the group of girls from Slovakia [7] is in favor of the girls of Slovak population in four indicators: sit and reach test, standing long jump, sit-ups and endurance shuttle run (Table 4). The girls from Banská Bystrica are better in flexed arm hang test and in one indicator of sit-and-reach, there are the same average values in both groups. When comparing our group of girls with a group of girls from eastern Slovakia, our girls are worse in trunk flexibility, dynamic and endurance strength of abdominal and hip-thigh muscles. But they are better in the following tests: standing long jump, flexed arm hang and endurance shuttle run.

When comparing with the group of boys from Slovakia [7] and with those from eastern Slovakia [8], we have recorded significantly higher level of physical development in our group of boys (Table 3). We noted different values of body height, body weight and BMI (Table 4) in a group of girls comparing them to the group from Slovakia [7] and to the group from eastern Slovakia [8].

We used two test batteries in this contribution-EUROFIT and UNIFIT. Based on analysis of numerically limited files, it was concluded that the diagnosis of motor skills of children

Table 3 Comparison of average results of our group with other researches-boys $(B)$.

\begin{tabular}{|c|c|c|c|c|c|c|c|c|c|c|}
\hline \multirow[t]{2}{*}{ B } & AGE & SRT & SLJ & SUT & FAH & $4 \times 10$ & ESR & $\mathrm{BH}$ & BW & BMI \\
\hline & & $(\mathrm{cm})$ & $(\mathrm{cm})$ & (n) & (s) & (s) & (n) & $(\mathrm{cm})$ & $(\mathrm{kg})$ & (i) \\
\hline $\begin{array}{l}\mathrm{BB}(2014) \\
n=220\end{array}$ & 10.37 & 16.28 & 151.93 & 19.75 & 25.45 & 12.8 & 37.08 & 144.75 & 38.78 & 18.36 \\
\hline $\begin{array}{l}\text { SR (1993) } \\
n=108\end{array}$ & 10.52 & 18.14 & 160.85 & 23.27 & 21.64 & & 43.56 & 143.52 & 36.35 & \\
\hline $\begin{array}{l}\text { East SR (1999) } \\
n=526\end{array}$ & 10 & 2.51 & 155.15 & 21.46 & 19.53 & & 31.87 & 141.14 & 33.73 & 17.48 \\
\hline
\end{tabular}

SRT: sit and reach test; SLJ: standing long jump; SUT: sit-ups; FAH: flexed arm hang; $4 \times 10$ : the shuttle run $4 \times 10$ m; ESR: endurance shuttle run; BH: body height; BW: body weight; BMI: body mass index.

Table 4 Comparison of average results of our group with other researches-girls (G).

\begin{tabular}{|c|c|c|c|c|c|c|c|c|c|c|}
\hline G & $\mathrm{AGE}$ & SRT & SLJ & SUT & FAH & $4 \times 10$ & ESR & $\mathrm{BH}$ & BW & BMI \\
\hline $\mathrm{x}$ & & $(\mathrm{cm})$ & $(\mathrm{cm})$ & (n) & (s) & (s) & (n) & $(\mathrm{cm})$ & $(\mathrm{kg})$ & (i) \\
\hline $\begin{array}{l}\mathrm{BB}(2014) \\
n=213\end{array}$ & 10.21 & 20.62 & 144.06 & 17.86 & 24.18 & 13.34 & 29.51 & 144.04 & 36.45 & 17.4 \\
\hline $\begin{array}{l}\text { SR (1993) } \\
n=116\end{array}$ & 10.55 & 21.89 & 150.05 & 21.61 & 11.78 & & 39.97 & 146.03 & 36.31 & \\
\hline $\begin{array}{l}\text { East SR } \\
(1999) \\
n=510\end{array}$ & 10 & 21.78 & 142.28 & 19.64 & 13.22 & & 23.37 & 140.67 & 33.58 & 19.49 \\
\hline
\end{tabular}

SRT: sit-and-reach test; SLJ: standing long jump; SUT: sit-ups; FAH: flexed arm hang; $4 \times 10$ : the shuttle run $4 \times 10 \mathrm{~m}$; ESR: endurance shuttle run; BH: body height; BW: body weight; BMI: body mass index. 
of younger-school-age is characterized by excessive width of "diagnostic coverage" [8, 27]. Therefore, we wanted to apply a battery that would cover the whole range of general physical performance, but through reducing the number of test items. We have omitted the test "flamingo" because of its lack of validity and questionable implementation in younger-school-age [8]. Whereas speed capabilities were investigated using another test (shuttle run $4 \times 10 \mathrm{~m}$ ), we omitted plate tapping which is used to measure frequency speed of upper limbs. We also omitted a hand dynamometer because we used the flexed arm hang test to find out a static strength of upper limbs. Instead of shuttle run $10 \times 5 \mathrm{~m}$, we used shuttle run $4 \times 10 \mathrm{~m}$, considering its duration and easier implementation. Although, the test $4 \times 10 \mathrm{~m}$ can be found in the battery UNIFIT, we simplified it considering the age of children. Our test battery, which we used in testing, is nearly identical to the Brown's test battery for sports talent identification [23].

\section{Conclusions}

The results that we noted in 10-year-old population of pupils in Banská Bystrica are similar as the test results of most Slovak authors, which says that boys are better than girls in the tests of general physical performance, except flexibility. In the indicators of physical development, we noted higher values in favor of boys.

When comparing with the subjects of the Slovak Republic [7], we state a lower level of general physical performance, except the test of flexed arm hang, but we state a higher level of physical development of tested boys and girls in Banská Bystrica. The comparing of the subjects from eastern Slovakia [8] shows bigger equality of both groups. Given the different selection of the subjects, our subjects were only the children from the town; the subjects of the Slovak Republic [7] and from eastern Slovakia [8] were the children both from the town and the village, we want to implement the testing on more representative subjects that would have affected the entire population of children.

The set of tests which we used affects the full range of general physical performance. When there is a sufficient number of examiners (6-8) in one class (20-25 students), it can be implemented in one lesson. It is not challenging the spatial and material support because it does not require special devices that are not in primary schools.

\section{Acknowledgments}

This contribution was written with the support of grant project KEGA 039UMB-4/2014 The innovation of tests of general physical performance of the school population between 6-15 years in region Banská Bystrica.

\section{References}

[1] Welk, G. J., and Blair, S. N. 2002. "Health Benefits of Physical Activity and Fitness in Children." In FITNESSGRAM Reference Guide, edited by Welk, G. J., Morrow J. R. J., and Falls, H. B. Dallas: The Cooper Institute, 10-27. Accessed October 10, 2014. http://www.fitneesgram.net.

[2] Sýkora, F. 1968. "Somatic Development and Physical Performance of Youth from Bratislava Aged from 7 to 18." Acta fac. Educ. Phys. Univ. Com. VII.: 179-257. (in Slovak)

[3] Šemetka, M. 1982. "Physical Development and Physical Performance of the Slovak Population aged from 7 to 14." Trainer 26 (1): 1-16. (in Slovak)

[4] Havlíček, I. Relative Motion Performance of the Youth Aged from 7 to 18 in CSFR and Its Comparison in Years 1966-1987. Bratislava: Ministry of Education and Youth of the Slovak Republic. (in Slovak)

[5] Moravec, R. 1990. Physical, Functional Development and Physical Performance of Youth Aged from 7 to 18 in CSFR. Bratislava: Ministry of Education and Youth of the Slovak Republic. (in Slovak)

[6] Kasa, J. 1997. "Evaluation of Physical Development and Motor Performance of 6-12 Years Old Children." In Physical Development and Physical Performance of Children and Youth, 211-5. (in Slovak)

[7] Moravec, R., Sedláček, J., Kampmiller, T., Ramacsay, L., Slamka, M., Šelingerová, M., Šimonek, J., Doležajová, L., Koštial, J., Plšíková, E., Čillík, I., and Medeková, H. 1996. EUROFIT Physique and Motor Fitness of the Slovak School Youth. Bratislava: Slovak Scientific 
Society for Physical Education and Sport. (in Slovak)

[8] Turek, M. 1999. Physical Development and Physical Performance of Children of Younger School Age. Prešov: The Eastern Slovak Society of Scientific Society for Physical Education and Sport. (in Slovak)

[9] Jančoková, L., Kremnický, J., Misárošová, M., Mišurová, D., Kompán, J., Jankovská, Ž., Bence, L., Rošková, M., Čillík, I., Bence, M., Palovičová, J., Hlasica, D., Nemec, M., Výboh, A., Rybárik, K., Starší, J., and Gorner, K. 2002. Monitoring of Physical Development, Functional Status and Physical Performance of Primary School Pupils in Banska Bystrica Region at the Beginning of the New Millennium. Banská Bystrica: Faculty of Humanities, Matej Bel University. (in Slovak)

[10] Trunečková, E., Adamčák, Š., Baisová, K., Bartík, P., Hrčka, J., Kollár, R., Krška, P., Mandzák, P., Novotná, N., Michal, J., Rozim, R., and Vladovičová, N. 2003. Sports Interests of Students and Teachers of the First Grade in Primary School and Their Somatic and Functional Characteristics. Banská Bystrica: Pedagogic Faculty, Matej Bel University. (in Slovak)

[11] Čillík, I., Kollár, R., Kremnický, J., Pivovarniček, P., Tokárová, M., Ďurják, O., Švachová, S., and Murínová, A. 2013. General Physical Performance and Physical Development of Pupils of the 1st Year of Primary School in Banská Bystrica in the School Year 2012/2013. Banská Bystrica: Faculty of Humanities, Matej Bel University. (in Slovak)

[12] Ružbarská, I., and Turek, M. 2007. Fitness and Coordination Skills in the Motor Skills of Children in Preschool and Younger School Age. Prešov: Faculty of Sport, University of Prešov. (in Slovak)

[13] Public Health Authority of the Slovak Republic. 2011. Accessed November 2013. http://www.uvzsr.sk/docs/info/hdm/Antropometria.pdf (in Slovak)

[14] Malina, R. M., Bouchard, C., and Bar-Or, O. 2004. Growth, Maturation, and Physical Activity. Champaign: Human Kinetics.
[15] Suchomel, A. 2006. Physically Unproficient Children of School Age. Liberec: Technical University. (in Czech)

[16] Gallahue, D. L., and Donnelly F. C. 2003. Development at Physical Education for All Children. Champaign: Human Kinetics.

[17] Haywood, K. M., and Getchel, N. N. 2005. Lifespan Motor Development. Champaign: Human Kinetics.

[18] EUROFIT: European Tests of Physical Fitness. 1988. Rome: Council of Europe, Comittee for the Development and Sport.

[19] Měkota, K., Kovář, R., Chytráčková, J., Gajda, V., Kohoutek, M., and Moravec, R. 1995. UNIFITTEST (660). Tests and Norms of Motor Performance and Physical Fitness in Youth and in Adult Age. Olomouc: Palacky University.

[20] Chytráčková, J. 2002. Unifitest. Praha: Faculty of Physical Education and Sport, Charles University.

[21] Cooper Institute. 1999. FITNESSGRAM. Test Administration Manual. 2nd revised ed. Champaign: Human Kinetics.

[22] Cooper Institute. 2004. FITNESSGRAM/ACTIVITYGRAM. Test Administration Manual. 3nd ed. Champaign: Human Kinetics.

[23] Brown, J. 2001: Sports Talent. Champaign: Human Kinetics.

[24] Šimonek, J. 2012. Tests of Motor Abilities. Nitra: Dominant. (in Slovak)

[25] Jančoková, L. 2000. Biorhythms in Sport (with the Introduction to Chronobiology). Banská Bystrica: Faculty of Humanities, Matej Bel University. (in Slovak)

[26] Kučera, M., Kolář, P., Dylevský, I., Bouška, I., Hátlová, B., Janda, J., Kálal, J., Máček, M., Nekola, J., Ošt’ádal, B., Otáhal, S., Perič, T., Radvanský, J., Ramba, J., Zeman, V., and Zounková, I. 2011. Child, Sports and Health. Praha: Galén. (in Czech)

[27] Turek, M. 1996. “Application of 'EUROFIT' Tests of Younger School Age Pupils.” In Conference Proceedings 4th International Scientific Conference, Sport Kinetics, 95: 479-83. 